\title{
Comunidade quilombola no sul brasileiro: identidade, memória e sustentabilidade no Vale do Ribeira
}

\author{
The Quilombola Community in southern of Brazil: \\ identity, memory and sustainability of Vale do Ribeira
}

\section{JuRANDIR DE SOUZA}

Antropólogo vinculado ao Museu Paranaense/SEEC-Pr, doutorando em Meio Ambiente e Desenvolvimento pela Universidade Federal do Paraná. jurandir@ufpr.br.br

\section{Resumo:}

O presente artigo pretende estabelecer uma reflexão acerca das comunidades quilombolas localizadas no estado do Paraná, em especial a comunidade do João Surá. O processo percorrido nos últimos anos da invisibilidade histórica à emancipação política, contribuiu para o lançamento das bases que vão proporcionar aos comunitários a reconstrução da sua identidade cultural. Mesmo que submetido aos pressupostos da sociedade hegemônica, estes atores sociais irão reforçar as suas práticas sociais como preservação da memória como resistência.

Palavras-chave: Identidade; Memória; Sustentabilidade

\section{Abstract:}

This article seeks to establish a reflection on the maroon communities located in the state of Paraná, in particular the community of John Sura. The process covered in the last years of historical invisibility political emancipation, helped to launch the grassroots community that will provide the reconstruction of their cultural identity. Even if subjected to the assumptions of the hegemonic society, these social actors will enhance their social practices as preserving the memory as resistance.

Keywords: Identity; Memory; Sustainability 


\section{Artigos \& Ensaios}

1 - As referências geográficas são: rio Pardo, ribeirão João Surá, Guaracuí, Forquilha, Poço Grande, Córrego Fundo ou Córrego da Porca, morro do Cachorro e morro do Juca da Mata.

2 - Informações do Grupo de Trabalho Clóvis Moura (GTCM), ligado a Secretaria de Assuntos Estratégicos do Estado o Paraná, SEAE/Pr.

3 - Dados de acordo com o IBGE 2000. análise sociológica a respeito de uma realidade depende de fórmulas
interpretativas de uma explicação racional e empírica, e assim, pode as-
segurar a compreensão das relaçóes sociais protagonizadas por grupos específicos (QUINTANEIRO, 2003).

Desta forma, as teorias sociais, mais do que esclarecer o fundamento das ações implementadas pelos indivíduos, ainda nos permite estabelecer métodos analíticos norteadores de como as comunidades tradicionais pensam a si e o mundo a sua volta.

Para Boaventura de Sousa Santos (2007), como é impossível criar uma teoria geral que dê conta da diversidade do mundo, ao menos nesse momento, é necessário buscar processos de "traduçáo" entre diferentes sistemas culturais que busquem a construção de outro mundo possível. Para tanto, devemos entender e conciliar as diferentes lutas dos oprimidos, no qual se inscreve as açóes sociais com recorte étnico.

Assim, podemos destacar as açóes encampadas pela comunidade remanescente de quilombo do João Surá. A comunidade está localizada a sessenta quilômetros da sede do município de Adrianópolis, regiáo do Alto Vale do Rio Ribeira do Iguape, na fronteira entre o Estado do Paraná e o Estado de São Paulo, nas áreas compreendidas pela confluência do rio Ribeira com o rio Pardo e os limites do atual Parque Estadual das Lauráceas.[1]

A comunidade foi formada há mais de duzentos anos no contexto de fugas da escravidão durante a atividade mineradora colonial no Alto do rio Ribeira. É é composta por descendentes de negras e de negros que, não aceitando a escravidão, fugiram da mina de ouro que existia em Apiaí (município localizado ao sul do estado SP) e estabeleceram vínculos de amizade com os índios que moravam nas proximidades do local onde atualmente estão as famílias negras.

Nos relatos colhidos na comunidade, entre os anos 2005 e 2010 [2], consta a fuga de um homem escravizado em uma das minas de ouro do Estado de São Paulo. Esse homem que se fingiu de morto fugiu para o local que era uma região composta por mata fechada com muito palmito, madeira de cerne e outras variedades. Ele começou a dar apoio às outras pessoas que chegaram também em busca de liberdade com seus diversificados conhecimentos e técnicas africanas. A comunidade é praticamente composta por parentes próximos, o que ressalta uma identidade familiar estreita, facilitando o contato e o respeito aos costumes dos (as) ancestrais. Seus membros evidenciam a singularidade característica deste segmento, ou seja, vivenciam o paradoxo entre resistir às modificaçóes vindas do exterior e a necessidade da adequação no mundo moderno.

Tal comunidade é parte de uma regiáo reconhecida pelo nome de Vale do Ribeira. Este localizado no sul do estado de São Paulo e norte do estado do Paraná, abrange a Bacia Hidrográfica do Rio Ribeira de Iguape e o Complexo Estuarino Lagunar de Iguape-Cananéia-Paranaguá. Sua área de 2.830.666 hectares abriga uma população de 481.224 habitantes [3] e inclui integralmente a área de 31 municípios ( 9 paranaenses e 22 paulistas). A região destaca-se ainda, pelo alto grau de preservação de suas matas e por grande diversidade ecológica. Seus mais de 2,1 milhóes de hectares de florestas equivalem a aproximadamente $21 \%$ dos remanescentes de Mata Atlântica existentes no Brasil, transformando-a na maior área contínua desse importante ecossistema em todo o País. Nesse conjunto de áreas preservadas são encontradas não apenas florestas, mas importantes remanescentes de restingas (são 150 mil hectares) e de manguezais (17 mil hectares). 
Diante do exposto, entendemos que nas sociedades modernas, nas quais se inclui o Brasil, têm-se criado movimentos sociais nos quais está em jogo a recuperação da auto-estima. Esta ocorrência tem trilhado caminhos que, algumas vezes, independem da delimitação de fronteiras, marcas e traços previamente definidos. Outras vezes, no entanto, é justamente a partir de limites, oposição, contrastes que se pode pensar numa re-inserção social via demarcação de fronteiras e ênfase na diferença.

As comunidades quilombolas do Brasil [4], assim como as demais comunidades tradicionais, por lutas e direitos, têm investido nas últimas décadas, no reconhecimento de suas identidades étnicas e coletivas através de encontros, seminários, cartografias sociais, atos públicos, dispositivos jurídicos entre outros, como estratégias de visibilidade social de seus direitos territoriais, promovendo a discussão do que Boaventura Sousa Santos (2002), definiu como a "Sociologia das Ausências", ou seja, na possibilidade de criticar a idéia de considerar o mundo ocidental como a única matriz na compreensão da realidade e das práticas sociais. Segundo o autor, para combater o desperdício da experiência social náo basta propor outro tipo de ciência social, mais do que isso, é necessário propor um modelo diferente de racionalidade, sem uma crítica ao modelo de racionalidade ocidental dominante, todas as propostas apresentadas pela nova análise social, por mais alternativas que se julguem, tenderão a reproduzir o mesmo efeito de ocultação e descrédito. (SOUSA SANTOS, 2002).

Por outro lado, mesmo que as categorias utilizadas e os mecanismos políticos reivindicatórios estejam, de certa forma, mediados pela sociedade hegemônica, é válido salientar, que tais intervençôes possuem uma perspectiva diferenciada, porque mantém um perfil indissociável como grupo excluído. Portanto, sublinhamos que a principal característica sociocultural das comunidades quilombolas em geral, entre as quais se inscreve a comunidade do João Surá, além da sua invisibilidade social, rodeada pelo estigma de um passado de atraso, é o de um presente de pobreza e conseqüentemente de abandono e preconceito.Partindo deste ponto de vista, podemos considerar que as sociedades tradicionais, em grande medida, estão submetidas as condiçóes determinadas pela sociedade hegemômica convencional fundamentada na Razão Indolente. Tal consistência ajuda desenvolver um aparato muito significativo, seguindo um plano de produção da não-existência, o que de certa forma, determinará as características da sociologia das ausências, que obedecerá as seguintes lógicas:

a) Monocultura do saber/rigor do saber;

b) Monocultura do tempo linear;

c) Lógica da classificação social, isto é, a naturalização das diferenças;

d) Lógica da escala dominante;

e) Lógica produtivista, com a aceitação de que o crescimento econômico é um objetivo racional inquestionável.

Tal mecanismo contribui para ocultar os pressupostos designados pelas sociedades tradicionais, e aponta para a dificuldade com que tais sociedades devem superar, principalmente no que se refere ao reconhecimento dos seus saberes e das suas singularidades.

Para Sousa Santos (2002), a luta pela credibilidade torna possível que a sociologia das ausências seja quebrada, permitindo alcançar o que ele chama de:
4 - Segundo Ilka Boaventura Leite, 2000, o quilombo constitui questão relevante desde os primeiros focos de resistência dos africanos ao escravismo colonial, reaparece no Brasil/República com a Frente Negra Brasileira (1930/40) e retorna à cena política no final dos anos 70, durante a redemocratização do país.Trata-se, portanto, de uma questão persistente, tendo na atualidade importante dimensão na luta dos afro-descendentes. Falar dos quilombos e dos quilombolas no cenário político atual é falar de uma luta política e, conseqüentemente, uma reflexão científica em processo de construção. 


\section{Artigos \& Ensaios}

5 - O sociólogo Clovis Moura (1987) demonstra que os aspectos legais que normatizam e orientam os direitos dos descendentes de africanos no Brasil, ressemantizadas na expressão "Quilombo" a partir da Constituição de 1988, abrange, os grupos autoreconhecidos por "Terras de Preto", Comunidades Negras Tradicionais, Comunidades Remanescentes de Quilombos, ou, propriamente, "Comunidades Quilombolas".
-Ecologia dos saberes: identifica outros critérios de saberes, dão credibilidade a contextos e práticas sociais declarados não existentes.

-Ecologia das temporalidades: o tempo linear não resulta da sua primazia enquanto concepçáo temporal, mas da adoção da modernidade ocidental partindo da atividade do camponês, do africano, ou asiático entregue a sua temporalidade própria, isto é, deixa de ser residual.

-Ecologia dos reconhecimentos: nova articulação entre princípio da igualdade e o princípio da diferença, abrindo espaço para a possibilidade de diferenças iguais, ecologia da diferença, feita de reconhecimento recíproco.

-Ecologia das transescalas: desglobalizar o local, relativamente à globalização hegemônica, trata-se de uma reglobalização, ampliando a diversidade das práticas sociais ao oferecer alternativas ao globalismo localizado.

-Ecologia da produtividade: consiste na recuperação, valorização dos sistemas alternativos de produção, das organizaçóes populares, das cooperativas operárias, das empresas autogeridas, da economia solidária,etc.

Para Max Weber (1979), as Ciências Sociais visam a compreensão de eventos culturais enquanto singularidades. $\mathrm{O}$ alvo é, portanto, captar a especificidade dos fenômenos estudados e seus significados. Mas sendo a realidade cultural infinita, uma investigaçáo exaustiva, que considerasse todas as circunstâncias ou variáveis envolvidas num determinado acontecimento, torna-se uma pretensão inatingível.

Assim, vale ressaltar que há menos de cinco anos as famílias intituladas quilombolas [5], desconheciam sua inserção no mundo contemporâneo, ignoravam sua posição geográfica, e não sabiam quantos e quais eram os conflitos a que estavam submetidas, além de quais as necessidades primordiais a que estão sujeitos.

O processo de produção da invisibilidade social tem suas raízes ancoradas nas atividades econômicas centradas nos diversos ciclos, iniciadas ainda no século XVII (mineração, gado, erva-mate, madeira), que conduziram a um modelo concentrador de terras para aqueles detentores de capital econômico e social. Assim, as comunidades Quilombolas, foram expulsas, eliminadas ou imobilizadas na sua força de trabalho.

Todos estes processos resultaram em pressóes contra estas comunidades que as induziram à negação de sua própria existência social e cultural, em benefício de empreendimentos econômicos, produtivos e ambientais de grande impacto social.

Assim temos: usinas hidrelétricas e mineradoras, grilagens de terras em áreas de apossamento, expansão do agronegócio, empreendimentos de lazer como chácaras, implantação de Unidades de Conservação e outros, além das condiçóes de fragilidade ambiental, geomorfológicas e de dificuldade de acesso na maioria destas áreas, que contribuíram para obliterar as condiçôes de reprodução física, social e cultural das comunidades.

Privados de sua territorialidade, e, assim alienados do seu modo de vida e produção, as comunidades quilombolas ainda têm buscado o caminho das periferias das grandes cidades e lá, sem educação formal e ou qualificação para qualquer trabalho, a elas lhes restam o subemprego e a miséria.

O Programa Brasil Quilombola, que desde 2004 faz parte do Plano Plurianual (PPA), vem priorizando açóes, destinando recursos e definindo metas para transpor as barreiras que separam as comunidades quilombolas do pleno exercício dos direitos de cidadania, garantia constitucional para todos os brasileiros e 
brasileiras.

Em 2005 no Paraná, na perspectiva de encontrar, identificar, mapear, e levantar as dificuldades das comunidades existentes, foi instituído o Grupo de Trabalho Clóvis Moura que teve o mérito de proporcionar além do conhecimento desta realidade, a possibilidade da garantia de um espaço para o exercício da plena cidadania para as comunidades mapeadas. Da invisibilidade, as comunidades quilombolas passam a buscar representatividade em espaços de decisão de políticas públicas tais como o Conselho Estadual de Desenvolvimento Rural da Agricultura Familiar, nos Conselhos Gestores dos Fóruns Territoriais nos Territórios da Cidadania, nos Conselhos Municipais de Desenvolvimento Rurais e nos Conselhos Municipais de Saúde, na busca de políticas para o atendimento das suas necessidades fundamentais.

Parcerias são institucionalizadas com órgãos do Governo Federal como o Incra, Eletrosul, Conab, com órgãos do Governo do Estado como a Secretaria do Meio Ambiente e Recursos Hídricos, através do ITCG, Secretaria da Agricultura e Abastecimento através do Instituto Emater, Secretaria da Educação, Copel e Sanepar, prefeituras municipais, Ministério Público do Paraná, Polícia Militar do Estado, mas principalmente com entidades da sociedade civil organizada que passam a perceber a dimensão da luta quilombola. Aqui se destaca a Rede de Mulheres Negras que possibilitou em 2007, no I Seminário Paranaense de Saúde e Saneamento para Comunidades Quilombolas, financiado pela Funasa, a primeira discussão sobre a necessidade de organizar as comunidades em Associação ou Federação e neste Encontro se formaliza a primeira comissão de criação da Federação de Comunidades Quilombolas.

A partir deste momento se inicia o processo de formação das associaçóes nas comunidades ainda não organizadas, com a formulação de seus estatutos e os devidos registros em cartórios de títulos documentos, abrindo assim a possibilidade das comunidades participarem legalmente dos programas e projetos de seus interesses como os Programas de Aquisição de Alimentos - PAA, participação em editais para Projetos de Assistência Técnica e Extensão Rural, Projetos de Resgate de Tradiçóes Culturais e outros.

Atualmente, as comunidades certificadas ou em processo de certificação já possuem suas entidades representativas devidamente legalizadas [6]. Neste processo de construçáo de cidadania as comunidades quilombolas localizadas no Vale do Ribeira, dando um exemplo de preocupação com a união de esforços e de trabalho conjunto, organiza o Comitê de Associaçóes de Comunidades Quilombolas do Vale do Ribeira - Coaquivale, localizadas nos municípios de Adrianópolis, Bocaiúva do Sul e Doutor Ulysses. É neste processo de formação das associaçóes por comunidades, com amplo apoio do Grupo de Trabalho Clóvis Moura e Eletrosul, na participação das lideranças nos encontros e debates promovidos pelas diferentes esferas do poder público que vai se cristalizando a proposta de criaçáo da Federação de Comunidades. Em julho de 2009, em Faxinal do Céu, no Município de Pinhão, no Encontro sobre Educação Quilombola e Políticas Públicas para Comunidades Remanescentes de Quilombolas, as comunidades presentes aprovam o estatuto da Fecoqui - Federação de Comunidades Quilombolas do Estado do Paraná.

O que se destaca deste processo é a rápida evolução destas comunidades que antes alijados de qualquer política pública, alienados de seu modo tradicional de vida e de produçáo, dissociados de sua identidade cultural, passam a se
6 - vale lembrar que as certidões são emitidas pela Fundação Cultural Palmares, e como aspecto fundamental é necessário o autoreconhecimento da comunidade. 


\section{Artigos \& Ensaios}

7 - muitos elementos subjetivos e explicativos estão contidos nas falas dos mais velhos, neles consiste a preservação da memória do grupo. perceber como cidadãos de direitos. Apesar de todas as dificuldades, dos grandes obstáculos nessa caminhada em busca do direito aos territórios e do exercício da plena cidadania, muitos são os avanços. Políticas de habitação, de Assistência Técnica no meio rural, de saúde diferenciada de uma educação quilombola, estão sendo construídas a partir do conhecimento das especificidades e da diversidade sociocultural na perspectiva de sustentabilidade ambiental, social, cultural, econômica e política. E esta construção só se fará com a participação das comunidades. E elas entenderam, em curto espaço de tempo, a importância das suas organizações.

Por mais incipientes e localizadas que tais ações representem, é possível reconhecer a grandeza do capital social e cultural, (BOURDIEU,1970), reunido durante este período nas comunidades remanescentes de quilombos. Além disso, podemos considerar que o seu habitus e práticas desenvolvidas por estas comunidades, também constituem um mecanismo de relevante compreensão teórica. [7]

Para Bourdieu,1972, as estruturas constitutivas de um tipo particular de meio podem ser apreendidas empiricamente sob a forma de regularidades associadas a um meio socialmente estruturado, produzindo um habitus, ou seja, sistemas de disposiçóes duráveis, funcionado como princípio gerador de práticas e representações que podem ser objetivamente adaptadas para um fim particular.

As práticas que o habitus produz são determinadas pela antecipação implícitas de suas conseqüências, isto é, tudo se passa como se as açóes se organizassem em relação às reações que aquelas exigem. O habitus está no princípio do encadeamento das açóes que são objetivamente organizadas como estratégicas.

Da mesma forma, as práticas podem encontrar-se ajustadas às chances objetivas, onde as disposiçóes inculcadas pelas condiçóes objetivas, criam aspiraçóes compatíveis com as condições, exigências e acontecimentos mais prováveis.

Assim, “...esta probabilidade que exclui a dúvida e cria uma certeza, que outras vezes só aparece como um clarão vacilante, é o que chamamos de probabilidade filosófica porque ela se refere ao exercício dessa faculdade superior pela qual nós nos damos conta da ordem e da razáo das coisas. O sentimento confuso de semelhantes probabilidades existe em todos os homens razoáveis, ele determina, entáo, ou ao menos justifica, as crenças inabaláveis que chamamos de senso comum"(BOURDIEU,1972, apud COURNOT,1922: 63).

Portanto, se o habitus pode funcionar enquanto operador que efetua a produção da prática, é porque a história produz a si mesma, ao incorporar as estruturas objetivas como natureza que são os próprios habitus. Em outras palavras, “... em cada um de nós, em proporções variáveis, há o homem de ontem; é o mesmo homem de ontem que, pela força das coisas, está predominante em nós, posto que o presente náo é senáo pouca coisa comparado a esse longo passado no curso do qual nos formamos e de onde resultamos."(Idem: 66).

Tal exposição nos aponta que as práticas sociais fundamentadas na construção e na permanência do habitus, assim como, na percepção holística homem-sociedade, ajuda na compreensão de que entre as comunidades quilombolas, o uso e atribuição das suas açóes racionais seguem um caminho passando, necessariamente, pelo compartilhamento e consentimento do grupo.

Esta percepção contribui para o fortalecimento de uma onda poderosa de identidade coletiva que desafia a globalização e o cosmopolitismo em função da singularidade cultural e autocontrole individual preconizado por Manuel Castells. Segundo o autor, do ponto de vista sociológico, "toda e qualquer identidade 
é construída" (CASTELLS,1999: 23). Esta construção vale-se de matéria prima fornecida por diversas fontes, porém todo este material é processado pelos indivíduos, grupos sociais e sociedades, que reorganizam seu significado em função de tendências sociais e projetos culturais que, embora enraizados em sua estrutura social, bem como em sua visão de tempo/espaço, adquirem funcionalidade política objetivando interesses contemporâneos. Em linhas gerais quem constrói a identidade coletiva, e para que essa identidade é construída, é em grande medida, o conteúdo simbólico dessa identidade, bem como o seu significado para aqueles que com ela se identificam ou dela se excluem. Para o autor é possível distinguir três formas e origens de construção de identidade:

- Identidade Legitimadora: introduzida pelas instituiçóes dominantes da sociedade no intuito de expandir e racionalizar sua dominaçáo em relaçáo aos atores sociais, tema este que está no cerne da teoria da autoridade e dominaçáo, e se aplica a diversas teorias do nacionalismo;

- Identidade de Resistência: criada por atores que se encontram em posições e condiçóes desvalorizadas e/ou estigmatizadas pela lógica da dominação, construindo, assim, trincheiras de resistência e sobrevivência com base em princípios diferentes dos que permeiam as instituiçóes da sociedade, ou mesmo opostos a estes últimos;

- Identidade como Projeto: quando os atores sociais utilizam-se de qualquer tipo de material cultural ao seu alcance, constróem uma nova identidade capaz de redefinir sua posição na sociedade e ao fazê-lo buscam a transformação de toda a estrutura social.

A discussão nos movimentos sociais e na política, como resultantes da interação entre a globalização induzida pela tecnologia, o poder da identidade e as instituiçóes do Estado faz uma lúcida análise dessa sociedade conectada pela convergência de telecomunicaçóes, computadores e redes. Enfatiza que devemos compreender a nossa contraditória pluralidade, por ser o multiculturalismo o fator transformador da globalização tecnoeconômica.

E finaliza, (...) Não existem movimentos sociais, bons ou maus, progressistas ou retrógrados. São eles reflexos do que somos, caminhos de nossa transformação... (CASTELLS, 2000: 20).

O obscurecimento político destes grupos sociais no Paraná explica, de certa forma, a incipiência dos levantamentos sobre a fauna e flora nessas comunidades. Segundo Claudemira Lopes (2010), há tempos as sociedades desta natureza utilizam os recursos naturais para preservar a memória material do grupo [8]. Estes reconhecem o poder medicinal de muitas plantas, evidenciam a ancestralidade africana presente nesse etnoconhecimento demonstram a importância da preservação da Floresta Atlântica tanto por sua vocação natural, quanto para a perpetuação do conhecimento e manejo das espécies desse bioma.

Toda e qualquer sociedade humana acumula um acervo de informaçóes sobre o meio onde vive, que lhe possibilita interagir e retirar desse meio o necessário para sua sobrevivência. Nesse estoque de informaçôes está o conhecimento que diz respeito ao mundo vegetal, o conhecimento etnobotânico (AMOROZO, 1996). No que se refere às comunidades quilombolas, esse acúmulo de conhecimentos possibilitou que resistissem até a contemporaneidade, apesar de terem sido desprovidas de qualquer tipo de política pública, inclusive as de saúde.

Não obstante, as comunidades quilombolas serem constituídas por pessoas oriundas de diversas etnias, o elemento negro lhe é preponderante. Culturalmen-
8 - ela pesquisou os usos que os quilombolas do Vale do Ribeira, em especial a comunidade do Varzeão, localizada no município de Dr. Ulysses-Pr, fazem de sua flora local a partir da razão prática. 
te, a relação homem/vegetal é de suma importância para o negro (BARROS, 1993). Ou seja, o indivíduo estabelece com os vegetais e animais, uma relação indissolúvel, que diz respeito à sua própria existência material, pois, a presença do sagrado em todas as coisas, a relação entre os mundos visível e invisível e entre os vivos e os mortos, é o sentido comunitário, o respeito religioso pela mãe e outros (HAMPÂTÉ BÂ, 2003).

Neste sentido, o uso de plantas como "remédios" em comunidades quilombolas precisa ser compreendido a partir de um contexto social e ecológico, levando-se em consideração os fatores culturais preservados na memória e nas etiologias das doenças para além do ambiente físico.

A mata nativa das regiôes quilombolas permanece praticamente intacta, a agricultura é de subsistência e a pesca, feita em canoas e redes produzidas à mão. Toda produção obedece a rituais seculares. É raro existir nestas comunidades práticas que não sejam, relativamente, sustentáveis. A preservação ambiental é a vocação natural do Vale do Ribeira e é a razão pela qual sociedades tradicionais dali convivem secularmente ao meio natural. Por isso, vários setores da sociedade vêm apostando em projetos de desenvolvimento sustentável na região.

Em contrapartida, propostas desenvolvimentistas são cada vez mais comuns, o que tem provocado um certo desequilíbrio nas relações entre os comunitários, sobretudo, nas açóes que estes devem estabelecer como prioridades coletivas. $\mathrm{O}$ princípio de seleção dos fenômenos culturais infinitamente diversos é subjetivo, portanto, apenas o ponto de vista humano é capaz de conferir-lhes sentido, assim, proceder à imputação de causas concretas e adequadas consiste na melhor forma de reconhecer a importância das práticas culturais como elementos alternativos.

Por isso, os quilombolas renovam sua tradição como mecanismo de resistência, sobretudo, a partir dos novos movimentos sociais (GOHN,1997), em que resistir à degradação do meio ambiente e à destruição da natureza, consiste na preservação da vida humana.

\section{REFERÊNCIAS BIBLIOGRÁFICAS}

ALMEIDA, Alfredo W. B. de. Terras de Preto, Terras de Santo, Terras de Índio Uso Comum e Conflito. Belém: NAEA/UFPA, 1989.

" "Comunidades tradicionais na resistência à expansão dos agronegó-

cios e à devastação do meio ambiente. http://www.cptpe.org.br/modules.php? name $=$ News\&file $=$ article\&sid=2862, acessado em 13/10/10.

AMOROZO, M. C. de M. "A abordagem etnobotânica na pesquisa de plantas medicinais". In: DI STASI, L.C (Org.). Plantas Medicinais: Arte e Ciência. Um Guia de Estudo Interdisciplinar. São Paulo: Editora da Universidade Estadual Paulista, 1996.

BARROS, J.F.P de. O Segredo das Folhas: Sistema de Classificação de Vegetais no Candomblé Jêje-Nagô do Brasil. Rio de Janeiro: Pallas/UERJ, 1993.

BOURDIEU, Pierre; PASSERON,Jean-Claude. A Reprodução: Elementos para Uma Teoria do Sistema de Ensino. Lisboa, 1970.

CASTELLS.Manuel. O Poder da Identidade. Oxforf: Blackwel,1997 .

GOHN.Maria da Glória. Teoria dos Movimentos Sociais: Paradigmas Clássicos e Contemporâneos.SP:Loyola, 1997.

HAMPATÊ BÂ, A. Amkoullel. O Menino Fula. São Paulo: Palas Athena: Casas das Africas, 2003.

LEITE, Ilka B. "Quilombos no Brasil: questôes conceituais e normativas". s/d. 
Artigos \& Ensaíos

www.cfh.ufsc.br/-nuer/artigos/osquilombos.htm, acessado em 28/02/2008.

LOPES, Claudemira.V.G. "O conhecimento etnobotânico da comunidade quilombola do Varzeão, Dr Ulysses (PR): no contexto do desenvolvimento rural sustentável”. 164 f. Tese (Doutorado em Ciências), Departamento de Produção Vegetal, Setor de Ciências Agronômicas, Universidade Federal do Paraná, Curitiba, 2010.

Relatório do Grupo de Trabalho Clóvis Moura, Série Terra e Cidadania, ITCG-Pr Curitiba, 2008.

SOUSA SANTOS. Boaventura de. A Crítica da Razão Indolente: Contra o Desperdicio da Experiência. Porto: Afrontamento, 2000.

QUINTANEIRO. Tânia. (et al). Um Toque de Clássicos. EDUFMG: Belo Horizonte. 2003.

- WEBER, Max. "A ciência como vocação". In: GERTH, Hans; MILLS, Wrigth. Max Weber. Ensaios de Sociologia. Tradução de Waltensir Dutra. RJ:Zahar,1979.

RESGATE - vol. XX, N² 24 - jul./dez. 2012 - DE SOUZA, Jurandir - p. 16-24

24 